\title{
Photodissociation Dynamics of the Ethoxy Radical $\left(\mathrm{C}_{2} \mathrm{H}_{5} \mathrm{O}\right)^{\dagger}$
}

\author{
Hyeon Choi, Ryan T. Bise, and Daniel M. Neumark* \\ Department of Chemistry, University of California, Berkeley, California 94720, and \\ Chemical Sciences Division, Lawrence Berkeley National Laboratory, Berkeley, California 94720
}

Received: January 25, 2000; In Final Form: March 21, 2000

\begin{abstract}
Photodissociation of the ethoxy $\left(\mathrm{C}_{2} \mathrm{H}_{5} \mathrm{O}\right)$ radical is investigated using photofragment translational spectroscopy. The ethoxy radical is generated by photodetachment of $\mathrm{C}_{2} \mathrm{H}_{5} \mathrm{O}^{-}$and subsequently dissociated by photon absorption in the range of $270-220 \mathrm{~nm}$; no dissociation is seen at higher wavelengths. The photofragment yield (PFY) spectrum is structureless but exhibits abrupt increases in intensity at 260 and $225 \mathrm{~nm}$. The product mass distribution shows that $\mathrm{C}_{2} \mathrm{H}_{5} \mathrm{O}$ dissociates into the vinyl radical $\left(\mathrm{C}_{2} \mathrm{H}_{3}\right)$ and $\mathrm{H}_{2} \mathrm{O}$ throughout the entire absorption band. We propose that these products are formed by isomerization and dissociation on electronically excited surfaces rather than by internal conversion to the ground state. The translational energy $\mathrm{P}\left(E_{\mathrm{T}}\right)$ distributions for this channel are largely insensitive to photon energy. However, at the two highest photon energies (5.51 and $5.96 \mathrm{eV}$ ), a new feature appears at $E_{\mathrm{T}} \leq 0.3 \mathrm{eV}$, which is assigned as production of an excited state of $\mathrm{C}_{2} \mathrm{H}_{3}$.
\end{abstract}

\section{Introduction}

Alkoxy radicals play a significant role as reaction intermediates in hydrocarbon combustion chemistry. The ethoxy $\left(\mathrm{C}_{2} \mathrm{H}_{5} \mathrm{O}\right)$ radical is particularly important, as it is believed to be a reaction intermediate in the $\mathrm{C}_{2} \mathrm{H}_{4}+\mathrm{OH}^{1-15}$ and $\mathrm{C}_{2} \mathrm{H}_{5}+\mathrm{O}$ reactions, ${ }^{16-18}$ undergoing dissociation to $\mathrm{CH}_{3}+\mathrm{CH}_{2} \mathrm{O}$ and $\mathrm{H}+\mathrm{CH}_{2} \mathrm{CHO}$. Absolute rate constants for thermal decomposition of ethoxy have been measured recently. ${ }^{19}$ However, the excited state photochemistry of the ethoxy radical is largely unknown. It is expected to be considerably more complex than in the methoxy radical, for which electronic excitation leads primarily to $\mathrm{CH}_{3}$ $+\mathrm{O}$ products, ${ }^{20}$ because ethoxy has many more low-lying dissociation channels: the four reactant and product channels listed above plus $\mathrm{C}_{2} \mathrm{H}_{3}+\mathrm{H}_{2} \mathrm{O}$ and $\mathrm{CH}_{3} \mathrm{CO}+\mathrm{H}_{2}$. In this paper, we present the first study of the photodissociation spectroscopy and dynamics of the ethoxy radical.

The electronic spectroscopy of $\mathrm{C}_{2} \mathrm{H}_{5} \mathrm{O}$ has been investigated in several laboratories. The emission spectrum from the $\tilde{\mathrm{B}}^{2} \mathrm{~A}^{\prime} \rightarrow$ $\tilde{\mathrm{X}}^{2} \mathrm{~A}^{\prime \prime}$ transition of the ethoxy radical was first observed in the range of 500-330 nm after photolysis of $\mathrm{C}_{2} \mathrm{H}_{5} \mathrm{ONO} .{ }^{21}$ Laserinduced fluorescence spectra were subsequently recorded in a gas cell by two different groups, showing the origin transition at $342.4 \mathrm{~nm}\left(29204 \mathrm{~cm}^{-1}\right)$ and a vibrational progression in the $\mathrm{C}-\mathrm{O}$ stretching mode. ${ }^{22,23}$ This set of measurements yielded a $\tilde{\mathrm{B}}^{2} \mathrm{~A}^{\prime}$ state radiative lifetime of $1-1.8 \mu \mathrm{s}$. Rotationally resolved laser-induced fluorescence was recorded for the origin and $9_{0}^{2}$ transitions. ${ }^{24,25}$ Recently, several additional vibrational modes of the $\tilde{\mathrm{X}}^{2} \mathrm{~A}^{\prime \prime}$ and $\tilde{\mathrm{B}}^{2} \mathrm{~A}^{\prime}$ states were assigned in a laser-induced fluorescence experiment by Zhu et al. ${ }^{26}$

Ruscic and Berkowitz ${ }^{27}$ found the ionization potential of ethoxy to be $10.29 \pm 0.08 \mathrm{eV}$ using photoionization mass spectrometry. Photoelectron (PES) spectra for the ethoxide anion were taken by the Lineberger ${ }^{28,29}$ and Ellison ${ }^{30}$ groups, and the electron affinity of the ethoxy radical was determined to be 1.712 $\pm 0.004 \mathrm{eV}$. In a recent PES spectrum by Lineberger and co-

$\dagger$ Part of the special issue "C. Bradley Moore Festschrift".

* Corresponding author. Email: dan@radon.cchem.berkeley.edu. workers, ${ }^{29}$ transitions to the ground $\left(\tilde{\mathrm{X}}^{2} \mathrm{~A}^{\prime \prime}\right)$ and low-lying excited $\left(\tilde{\mathrm{A}}^{2} A^{\prime}\right)$ states of $\mathrm{C}_{2} \mathrm{H}_{5} \mathrm{O}$ radical were resolved; these states are separated by only $355 \pm 10 \mathrm{~cm}^{-1}$ and are distinguished by their photoelectron angular distributions.

An interesting property of $\mathrm{C}_{2} \mathrm{H}_{5} \mathrm{O}$ particularly relevant to the results presented in this paper is the existence of chemically distinct isomers. Two stable isomers are known in addition to ethoxy radical $\left(\mathrm{CH}_{3} \mathrm{CH}_{2} \mathrm{O}\right)$ : the 1-hydroxyethyl $\left(\mathrm{CH}_{3} \mathrm{CHOH}\right)$ and 2-hydroxyethyl $\left(\mathrm{CH}_{2} \mathrm{CH}_{2} \mathrm{OH}\right)$ radicals. These chemically important species are less well characterized than the ethoxy radical. Anastasi et al. ${ }^{31,32}$ observed broad absorption spectra for both radicals in the range of $300-210 \mathrm{~nm}$ using a pulse radiolysis/kinetic absorption technique, although their assignment of the $\mathrm{CH}_{2} \mathrm{CH}_{2} \mathrm{OH}$ spectrum is called into question by the results reported here. The ionization potential of $\mathrm{CH}_{3} \mathrm{CHOH}$ was measured to be $<6.85 \mathrm{eV}$ by photoionization mass spectrometry; ${ }^{27}$ a more precise value of $6.64 \pm 0.03 \mathrm{eV}$ was recently obtained by Dyke et al. ${ }^{33}$ using photoelectron spectroscopy.

Energetics of the three isomers were calculated by Schlegel and co-workers ${ }^{34,35}$ and Curtiss et al. ${ }^{36}$ In both studies, $\mathrm{CH}_{3}$ $\mathrm{CHOH}$ was found to be the most stable isomer, followed by $\mathrm{CH}_{2} \mathrm{CH}_{2} \mathrm{OH}$ and then $\mathrm{CH}_{3} \mathrm{CH}_{2} \mathrm{O}$, with all three isomers lying within a $0.5-\mathrm{eV}$ energy range. $\mathrm{Ab}$ initio calculations have also been applied to geometric isomers of the $\mathrm{C}_{2} \mathrm{H}_{5} \mathrm{O}^{-}$anion and the $\mathrm{C}_{2} \mathrm{H}_{5} \mathrm{O}^{+}$cation by Chiu et al. ${ }^{37}$ and Curtiss et al., ${ }^{36}$ respectively. The ethoxide anion was found to lie almost $1 \mathrm{eV}$ below the next most stable structure $\left(\mathrm{CH}_{2} \mathrm{CH}_{2} \mathrm{OH}^{-}\right)$, whereas $\mathrm{CH}_{3} \mathrm{CHOH}^{+}$was the most stable cation.

The role of isomerization in the reaction dynamics of $\mathrm{C}_{2} \mathrm{H}_{5} \mathrm{O}$ was investigated in the ab initio studies by Schlegel and coworkers ${ }^{34,35}$ and Hoyermann et al., ${ }^{18}$ both of whom calculated barrier heights for various isomerization and dissociation processes. Schlegel found the most facile path for the $\mathrm{OH}+$ $\mathrm{C}_{2} \mathrm{H}_{4}$ reaction be the addition of $\mathrm{OH}$ to $\mathrm{C}_{2} \mathrm{H}_{4}$ to form $\mathrm{CH}_{2} \mathrm{CH}_{2}-$ $\mathrm{OH}$, followed by isomerization to ethoxy radical over a 1.2-eV barrier and dissociation to $\mathrm{CH}_{3}+\mathrm{CH}_{2} \mathrm{O}$. On the other hand, isomerization does not appear to be important in the thermal ${ }^{19}$ 
or chemically activated ${ }^{18}$ decomposition of ethoxy itself, as the two observed channels, $\mathrm{CH}_{3}+\mathrm{CH}_{2} \mathrm{O}$ and $\mathrm{H}+\mathrm{CH}_{2} \mathrm{CHO}$, result from simple bond fission.

In this paper, we investigate the photodissociation dynamics of $\mathrm{C}_{2} \mathrm{H}_{5} \mathrm{O}$ using our fast radical beam photofragment spectrometer. Here, a beam of $\mathrm{C}_{2} \mathrm{H}_{5} \mathrm{O}$ neutrals is prepared by laser photodetachment of mass-selected $\mathrm{C}_{2} \mathrm{H}_{5} \mathrm{O}^{-}$ions and subsequently photodissociated by a second laser. We observe photodissociation from a previously unknown electronic band of ethoxy and identify the dissociation products as $\mathrm{C}_{2} \mathrm{H}_{3}+\mathrm{H}_{2} \mathrm{O}$ using our time- and position-sensitive detector. The observation of this channel suggests that isomerization plays a significant role in the excited-state dissociation dynamics of ethoxy, in contrast to the ground-state dynamics.

\section{Experimental Setup}

The fast radical beam photofragmentation apparatus has been described in detail previously. ${ }^{38,39}$ Briefly, oxygen gas (40 psi) bubbles through ethanol $\left(\mathrm{C}_{2} \mathrm{H}_{5} \mathrm{OH}\right)$ at $0{ }^{\circ} \mathrm{C}$. The resulting mixture supersonically expands through a pulsed value and electric discharge channel into the source region of the apparatus. ${ }^{40}$ Ions are created in the discharge channel by applying a voltage pulse of $-600 \mathrm{~V}$ just after the valve opens and cooling to $\sim 50 \mathrm{~K}^{41}$ during expansion. Deuterated ethoxide, $\mathrm{C}_{2} \mathrm{D}_{5} \mathrm{O}^{-}$, was produced by the same method.

Negative ions formed in the source region are accelerated to $6 \mathrm{keV}$ and separated temporally by a time-of-flight (TOF) mass spectrometer. The $\mathrm{C}_{2} \mathrm{H}_{5} \mathrm{O}^{-}$ion packet is intersected by an excimer-pumped pulsed dye laser beam, photodetaching some anions to yield neutral $\mathrm{C}_{2} \mathrm{H}_{5} \mathrm{O}$ radicals. The photon energy used in these experiments, $1.80 \mathrm{eV}$, is just above the detachment threshold for the $\tilde{\mathrm{A}}{ }^{2} \mathrm{~A}^{\prime}$ state of the ethoxy radical, ${ }^{29}$ so both the $\tilde{\mathrm{X}}^{2} \mathrm{~A}^{\prime \prime}$ and $\tilde{\mathrm{A}}{ }^{2} \mathrm{~A}^{\prime}$ states are populated in our radical beam, albeit with no vibrational excitation in either state. Since ethoxide is predicted ${ }^{37}$ to be the lowest-energy anion structure, no other isomers are expected in the anion beam. This is supported by the absence of photodetachment below the electron affinity of ethoxy radical, because any other isomers would have considerably lower vertical detachment energies. ${ }^{34,36,37}$

Any remaining ions after the photodetachment pulse are removed by application of an electrical deflection pulse. The neutral beam is then crossed by a second excimer-pumped tunable dye laser beam. The resulting photofragments are detected by microchannel plates with high efficiency $(\sim 50 \%)$ because of the high laboratory kinetic energy ( $6 \mathrm{keV})$. A beam block prevents undissociated radicals from impinging on the detector, whereas the photofragments with sufficient recoil energy $E_{\mathrm{T}}$ clear the beam block and strike the detector.

Two types of experiments are performed. First, the photofragment yield (PFY) spectrum is obtained by collecting the total flux of fragments as a function of the photodissociation laser wavelength. Second, at selected photon energies, the photofragments are collected in coincidence using a time- and position-sensitive detector. By measuring the distance between the photofragments and the interval between their arrival times, we obtain the fragment masses, translational energy release, and scattering angle for each photodissociation event. From these, we obtain the translational energy $\mathrm{P}\left(E_{\mathrm{T}}\right)$ distributions for each product mass channel.

The fragment masses are determined by the distance of the two fragments from the center of the detector. As a consequence, the fragment mass resolution mainly depends on the diameter of the parent radical beam at the detector. This diameter is around $1 \mathrm{~mm}$, yielding a fragment mass resolution $(\mathrm{m} / \Delta \mathrm{m})$ of $\sim 10$.

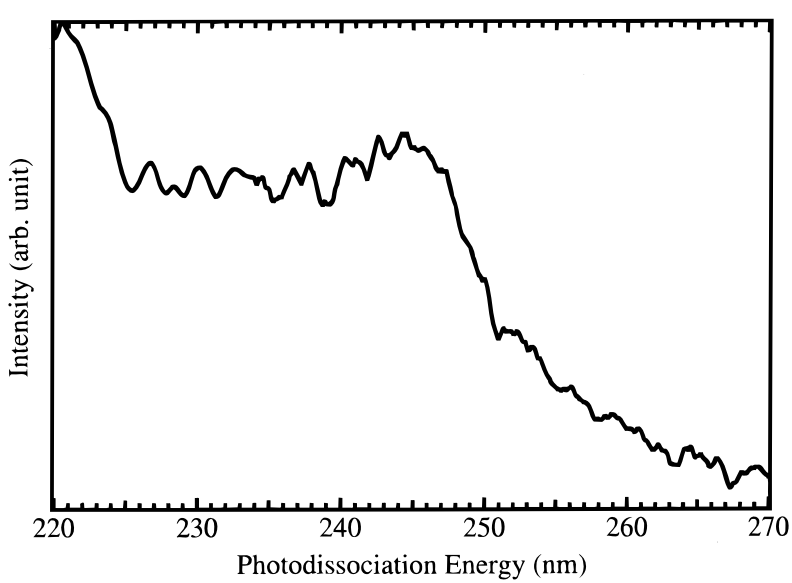

Figure 1. Photofragment yield (PFY) spectrum of $\mathrm{C}_{2} \mathrm{H}_{5} \mathrm{O}$.

In the coincidence experiment, the flight length from the photodissociation laser to the detector can be varied to optimize collection of low or high translational energy fragments. At longer flight lengths, more low-energy fragments clear the beam block and hit the detector, but more high energy fragments miss the detector because of its finite size (40-mm diameter). In this paper, most of $\mathrm{P}\left(E_{\mathrm{T}}\right)$ distributions are obtained at a 1-m flight length, whereas some $\mathrm{P}\left(E_{\mathrm{T}}\right)$ distributions are obtained at a 2-m flight length to enhance detection of low-energy product. In either case, the $\mathrm{P}\left(E_{\mathrm{T}}\right)$ distributions are generated from the raw data using a "detector acceptance function" that accounts for these effects. ${ }^{42}$

\section{Results}

A. Photofragment Yield (PFY) Spectrum of $\mathbf{C}_{2} \mathbf{H}_{5} \mathrm{O}$. The PFY spectrum obtained from $\mathrm{C}_{2} \mathrm{H}_{5} \mathrm{O}$ is shown in Figure 1. This spectrum covers $270-220 \mathrm{~nm}(4.59-5.64 \mathrm{eV})$ with $0.04-\mathrm{nm}$ steps. No additional structure is resolved with finer step sizes. No significant dissociation signal was observed in the region of $342-311 \mathrm{~nm}$, where laser-induced fluorescence from the $\tilde{\mathrm{B}}$ ${ }^{2} \mathrm{~A}^{\prime} \rightarrow \tilde{\mathrm{X}}{ }^{2} \mathrm{~A}^{\prime \prime}$ transition of $\mathrm{C}_{2} \mathrm{H}_{5} \mathrm{O}$ radicals was previously reported..$^{22,23,26}$ The photofragment flux increases around 260 and $225 \mathrm{~nm}$.

B. Product Mass Distribution. Several dissociation channels are energetically accessible in the photon energy range of Figure $1: 43-45$

$$
\begin{aligned}
\mathrm{C}_{2} \mathrm{H}_{5} \mathrm{O}\left(\tilde{\mathrm{X}}^{2} \mathrm{~A}^{\prime \prime}\right)+h v \rightarrow \mathrm{CH}_{3} \mathrm{CO}+\mathrm{H}_{2} & \\
\Delta_{\mathrm{r}} \mathrm{H}_{0} & =-0.24 \mathrm{eV} \\
\mathrm{CH}_{2} \mathrm{O}+\mathrm{CH}_{3} & =0.40 \mathrm{eV} \\
\mathrm{CH}_{3} \mathrm{CHO}+\mathrm{H} & =0.65 \mathrm{eV} \\
\mathrm{C}_{2} \mathrm{H}_{3}+\mathrm{H}_{2} \mathrm{O} & =0.69 \mathrm{eV} \\
\mathrm{C}_{2} \mathrm{H}_{4}+\mathrm{OH} & =1.05 \mathrm{eV} \\
\mathrm{C}_{2} \mathrm{H}_{5}+\mathrm{O} & =3.92 \mathrm{eV}
\end{aligned}
$$

The coincidence detection scheme works well only if the fragment mass ratio is less than 5:1; otherwise, the heavy fragment is generally blocked by the beam block and/or the light fragment misses the detector. Consequently, channels 1 and 3 cannot be detected in this experiment. 


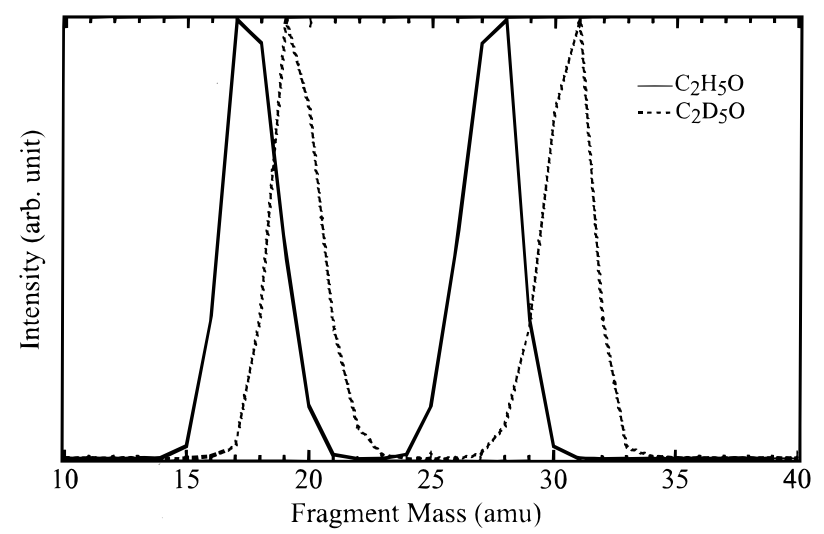

Figure 2. Photofragment mass spectrum of $\mathrm{C}_{2} \mathrm{H}_{5} \mathrm{O}$ (solid) and $\mathrm{C}_{2} \mathrm{D}_{5} \mathrm{O}$ (dashed).

(a) $\mathrm{C}_{2} \mathrm{H}_{5} \mathrm{O} \rightarrow \mathrm{C}_{2} \mathrm{H}_{3}+\mathrm{H}_{2} \mathrm{O}$

(b) $\mathrm{C}_{2} \mathrm{D}_{5} \mathrm{O} \rightarrow \mathrm{C}_{2} \mathrm{D}_{3}+\mathrm{D}_{2} \mathrm{O}$

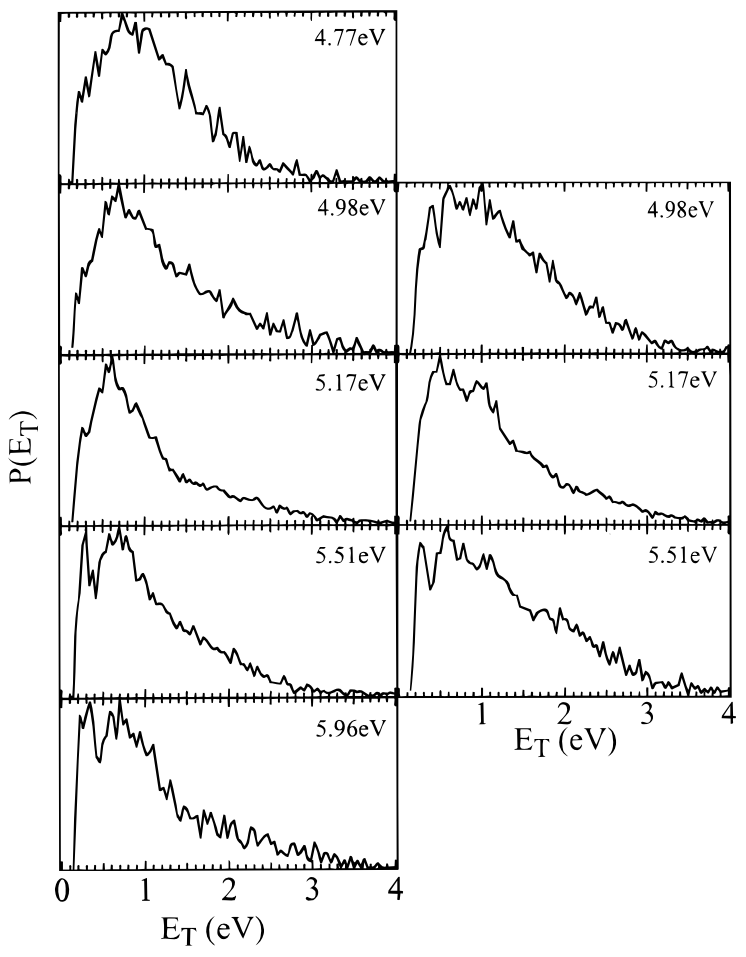

Figure 3. Translational energy distributions $\mathrm{P}\left(E_{\mathrm{T}}\right)$ of (a) $\mathrm{C}_{2} \mathrm{H}_{5} \mathrm{O}$ and (b) $\mathrm{C}_{2} \mathrm{D}_{5} \mathrm{O}$ at selected excitation energies. Flight length was $1 \mathrm{~m}$.

Figure 2 shows the product mass distribution for $\mathrm{C}_{2} \mathrm{H}_{5} \mathrm{O}$ and $\mathrm{C}_{2} \mathrm{D}_{5} \mathrm{O}$ photodissociation at $5.17 \mathrm{eV}$. For $\mathrm{C}_{2} \mathrm{H}_{5} \mathrm{O}$ photodissociation, the average photofragment masses are 17.6 and 27.4 amu for the light and heavy masses, respectively, a result that could originate from channel 4 and/or 5 given our relatively poor fragment mass resolution. However, isotopic substitution from $\mathrm{C}_{2} \mathrm{H}_{5} \mathrm{O}$ to $\mathrm{C}_{2} \mathrm{D}_{5} \mathrm{O}$ results in a shift of $2 \mathrm{amu}$ for the light mass and 3 amu for the heavy mass while showing no increase in peak width, indicating that there are two hydrogen atoms on the light fragment and three on the heavy fragment. There is no significant change in mass distribution or isotope shift, neither over the range of photon energies investigated here nor over the translational energy range at a particular photon energy. Hence, channel $4, \mathrm{C}_{2} \mathrm{H}_{3}+\mathrm{H}_{2} \mathrm{O}$, appears to be the dominant dissociation channel for which the product mass ratio is less than 5:1.

C. Translational Energy $\mathrm{P}\left(E_{\mathrm{T}}\right)$ Distributions of $\mathrm{C}_{2} \mathrm{H}_{5} \mathrm{O}$ and $\mathbf{C}_{2} \mathbf{D}_{5} \mathbf{O}$. Figure 3 shows $\mathrm{P}\left(E_{\mathrm{T}}\right)$ distributions for $\mathrm{C}_{2} \mathrm{H}_{3}+\mathrm{H}_{2} \mathrm{O}$

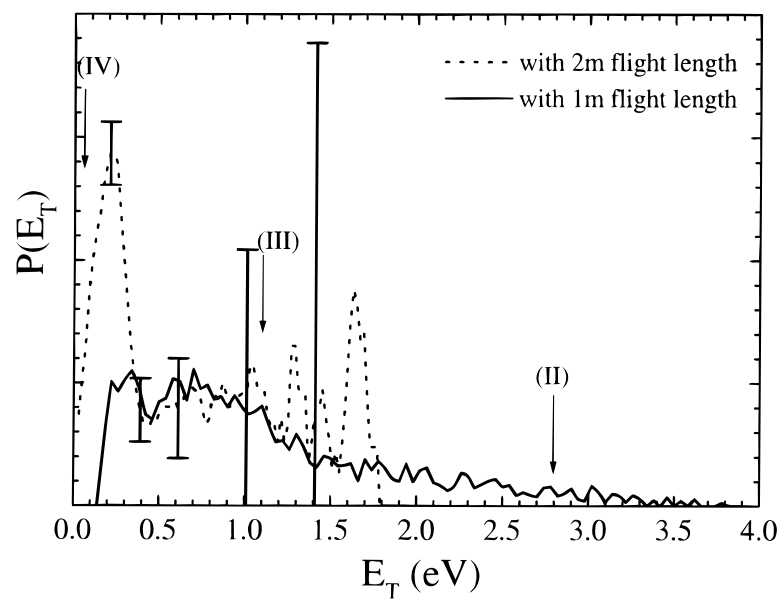

Figure 4. Translational energy distributions $\mathrm{P}\left(E_{\mathrm{T}}\right)$ of $\mathrm{C}_{2} \mathrm{H}_{5} \mathrm{O}$ at 5.96 $\mathrm{eV}$ at flight lengths of $1 \mathrm{~m}$ (solid) and $2 \mathrm{~m}$ (dashed). Arrows indicate the maximum $E_{\mathrm{T}}$ for channels II-IV.

from $\mathrm{C}_{2} \mathrm{H}_{5} \mathrm{O}$ and $\mathrm{C}_{2} \mathrm{D}_{5} \mathrm{O}$ at selected photon energies using a flight length of $1 \mathrm{~m} . \mathrm{P}\left(E_{\mathrm{T}}\right)$ distributions from $\mathrm{C}_{2} \mathrm{H}_{5} \mathrm{O}$ are shown on the left side of Figure 3, and those from $\mathrm{C}_{2} \mathrm{D}_{5} \mathrm{O}$ are shown on the right side of Figure 3.

For $\mathrm{C}_{2} \mathrm{H}_{5} \mathrm{O}$ dissociation at $h v \leq 5.17 \mathrm{eV}$, the $\mathrm{P}\left(E_{\mathrm{T}}\right)$ distributions show a single feature, peaking around $0.7 \mathrm{eV}$ and extending to $4 \mathrm{eV}$. This feature narrows somewhat as the photon energy is raised. The $\mathrm{P}\left(E_{\mathrm{T}}\right)$ distributions for $\mathrm{C}_{2} \mathrm{D}_{5} \mathrm{O}$ dissociation at the same photon energies have the same general shape, although the peak is slightly broader toward high $E_{\mathrm{T}}$. For $h v \geq$ $5.51 \mathrm{eV}$, a new peak appears around $E_{\mathrm{T}}=0.3 \mathrm{eV}$. At a $1-\mathrm{m}$ flight length, most of the signal at $E_{\mathrm{T}} \leq 0.3 \mathrm{eV}$ is blocked, so the flight length was increased to $2 \mathrm{~m}$ to better investigate this new feature.

Figure 4 shows the $\mathrm{P}\left(E_{\mathrm{T}}\right)$ distributions of $\mathrm{C}_{2} \mathrm{H}_{5} \mathrm{O}$ obtained at $5.96 \mathrm{eV}$ at flight lengths of $1 \mathrm{~m}$ (solid) and $2 \mathrm{~m}$ (dotted). The distribution at $2 \mathrm{~m}$ is now dominated by the low-energy feature, which appears to peak at an energy even lower than $0.3 \mathrm{eV}$. Note that the error bars for the data with a $2 \mathrm{~m}$ flight length increase dramatically above $1.0 \mathrm{eV}$ due to the poor collection efficiency of the fragments, because many of the lighter fragments $\left(\mathrm{H}_{2} \mathrm{O}\right)$ miss the detector.

D. $\boldsymbol{A} \boldsymbol{b}$ initio Calculations. Dissociation from any of the $\mathrm{C}_{2} \mathrm{H}_{5} \mathrm{O}$ isomers to $\mathrm{C}_{2} \mathrm{H}_{3}+\mathrm{H}_{2} \mathrm{O}$ has not been previously considered in ab initio studies on this system, so we performed our own calculations to find and characterize a plausible transition state leading to these products. Using the MP2 method with a 6-31G* basis within the GAUSSIAN 92 suite of<smiles>OC1CCC1</smiles>

programs, ${ }^{46}$ we located the four-centered transition state (I) leading from 1-hydroxyethyl to $\mathrm{C}_{2} \mathrm{H}_{3}+\mathrm{H}_{2} \mathrm{O}$. The geometry of the transition state (TS) is shown in Figure 5. This TS has one imaginary frequency, involving the hydrogen $\left(\mathrm{H}_{5}\right.$ in Figure 5) motion between $\mathrm{O}$ and $\mathrm{C}$ atoms and the $\mathrm{C}-\mathrm{O}$ stretch. To find the relative energy of this species with respect to the ethoxy radical, we carried out a calculation for ethoxy radical at the same level of theory and found the TS to lie $3.23 \mathrm{eV}$ above the ethoxy radical.

Figure 6 shows the relative energies of ethoxy, 1-hydroxyethyl $\left(\mathrm{CH}_{3} \mathrm{CHOH}\right)$, and 2-hydroxyethyl radicals using the calculations by Curtiss et al. ${ }^{36}$ for the isomer energies, our result for the 


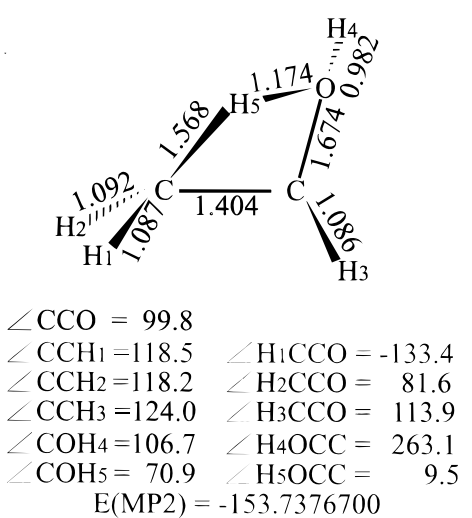

Figure 5. Geometry and energy of the four-centered transition state at the MP2/6-31G* level of calculation. Bond length is in $\AA$, bond angle is in degrees, and energy is in Hartrees. $\angle \mathrm{ABCD}$ corresponds to the dihedral angle between $\mathrm{ABC}$ and $\mathrm{BCD}$ planes.

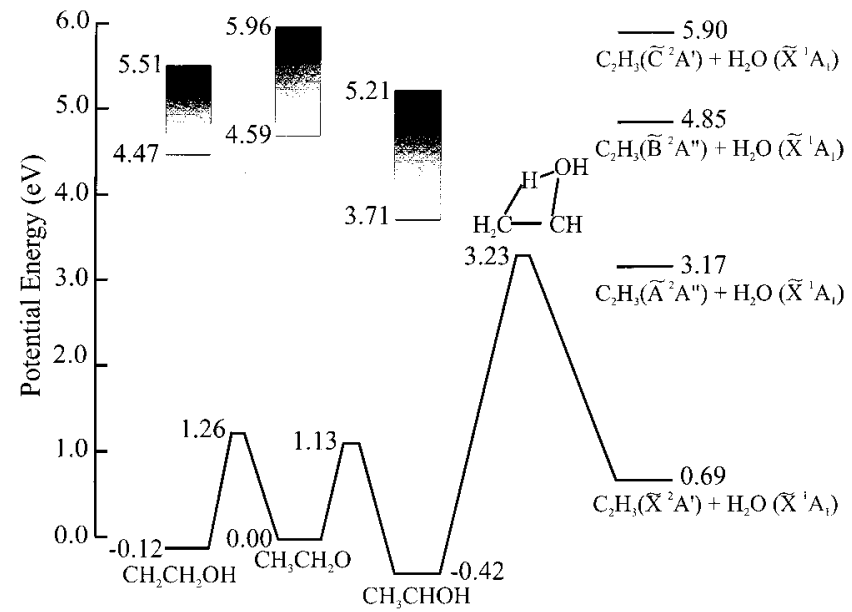

Figure 6. Potential energy diagram for $\mathrm{C}_{2} \mathrm{H}_{5} \mathrm{O}$. Relative energies of $\mathrm{C}_{2} \mathrm{H}_{5} \mathrm{O}$ isomers and isomerization barrier heights on the ground state are obtained from refs 18 and 36 except for the four-centered transition state, which is from the present work. Filled boxes represent absorption bands observed by us for the ethoxy radical $\left(\mathrm{C}_{2} \mathrm{H}_{5} \mathrm{O}\right)$ and by Anastasi et al. ${ }^{31,32}$ for the 1-hydroxyethyl $\left(\mathrm{CH}_{3} \mathrm{CHOH}\right)$ and the 2-hydroxyethyl $\left(\mathrm{CH}_{2} \mathrm{CH}_{2} \mathrm{OH}\right)$ radicals. Relative energies for the photoproducts are determined using values in refs $52-54$.

four-centered transition state, and the isomerization barrier heights calculated by Hoyermann et al. ${ }^{18}$ For the three stable isomers, we also show the energy interval over which electronic excitation was observed based on our PFY spectrum (for ethoxy radical) and the absorption spectra by Anastasi et al. ${ }^{31,32}$ for the other two radicals.

\section{Discussion}

In this section, we consider the origin of the diffuse band in the PFY spectrum and the dissociation mechanism associated with excitation of this band.

A. Origin of the Diffuse Band in the PFY Spectrum. Our PFY spectrum shows a broad band extending from 270 to 220 $\mathrm{nm}$, with intensity jumps at $260 \mathrm{~nm}$ and $225 \mathrm{~nm}$. This band lies well to the blue of the $\tilde{\mathrm{B}}^{2} \mathrm{~A}^{\prime}-\tilde{\mathrm{X}}^{2} \mathrm{~A}^{\prime \prime}$ transition, a highly structured band covering 342-311 $\mathrm{nm}$ that has been seen previously using laser-induced fluorescence. It therefore appears likely that we are observing a new electronic transition in $\mathrm{C}_{2} \mathrm{H}_{5} \mathrm{O}$ rather than the blue tail of the $\tilde{\mathrm{B}}^{2} \mathrm{~A}^{\prime} \rightarrow \tilde{\mathrm{X}}{ }^{2} \mathrm{~A}^{\prime \prime}$ transition.

The $\tilde{\mathrm{B}}^{2} \mathrm{~A}^{\prime}-\tilde{\mathrm{X}}^{2} \mathrm{~A}^{\prime \prime}$ transition in ethoxy is similar to the wellstudied $\tilde{\mathrm{A}}{ }^{2} \mathrm{~A}_{1}-\tilde{\mathrm{X}}{ }^{2} \mathrm{E}$ transition in the methoxy $\left(\mathrm{CH}_{3} \mathrm{O}\right)$ radi- cal. ${ }^{20,47}$ Both occur in approximately the same energy range and show significant vibrational activity in the $\mathrm{C}-\mathrm{O}$ stretch $\left(\nu_{3}\right.$ in $\mathrm{CH}_{3} \mathrm{O}$, and $v_{10}$ in $\mathrm{C}_{2} \mathrm{H}_{5} \mathrm{O}$ ), and both have been assigned to excitation of a $\mathrm{C}-\mathrm{O} \sigma$-bonding electron into a half-filled $\mathrm{p} \pi$ localized on the $\mathrm{O}$ atom. More specifically, the ground state of $\mathrm{C}_{2} \mathrm{H}_{5} \mathrm{O}$ has the electronic configuration ...(8 $\left.8 \mathrm{a}^{\prime}\right)^{2}\left(2 \mathrm{a}^{\prime \prime}\right)^{2}\left(9 \mathrm{a}^{\prime}\right)^{2}-$ $\left(10 a^{\prime}\right)^{2}\left(3 a^{\prime \prime}\right)^{1}$. The $3 a^{\prime \prime}$ and $10 a^{\prime}$ orbitals are $\mathrm{O} \pi$ orbitals, the $9 \mathrm{a}^{\prime}$ orbital is the $\mathrm{C}-\mathrm{O} \sigma$ orbital, and the $\tilde{\mathrm{B}}{ }^{2} \mathrm{~A}^{\prime} \rightarrow \tilde{\mathrm{X}}{ }^{2} \mathrm{~A}^{\prime \prime}$ transition corresponds to $3 \mathrm{a}^{\prime \prime} \leftarrow 9 \mathrm{a}^{\prime}$ excitation. The PFY spectrum in Figure 1 appears to consist of two electronic bands, with the higher-energy band commencing at $225 \mathrm{~nm}$. We tentatively assign these two bands to excitation of the $2 \mathrm{a}^{\prime \prime}(\mathrm{C}-\mathrm{H}$ $\sigma$ of $\mathrm{CH}_{3}$ component in $\left.\mathrm{C}_{2} \mathrm{H}_{5} \mathrm{O}\right)$ and $8 \mathrm{a}^{\prime}(\mathrm{C}-\mathrm{C} \sigma$ and $\mathrm{C}-\mathrm{O} \sigma)$ electrons to the half-filled $\mathrm{O} \mathrm{p} \pi$ orbital.

Note that the $\tilde{\mathrm{A}}{ }^{2} \mathrm{~A}^{\prime}$ state of ethoxy is also formed at the photodetachment energy used to generate the radicals. This state, which lies only $350 \mathrm{~cm}^{-1}$ above the ground state, ${ }^{29}$ has the electronic configuration ... $\left(10 \mathrm{a}^{\prime}\right)^{1}\left(3 \mathrm{a}^{\prime \prime}\right)^{2}$ and differs from the $\tilde{\mathrm{X}}^{2} \mathrm{~A}^{\prime \prime}$ state only in the orientation of the half-filled $\mathrm{O} \mathrm{p} \pi$ orbital. Hence, transitions originating from the $\tilde{\mathrm{A}}^{2} \mathrm{~A}^{\prime}$ state should also contribute to the PFY spectrum in Figure 1. However, based on the above assignment, the upper state will be the same as for the transitions originating from the $\tilde{\mathrm{X}}^{2} \mathrm{~A}^{\prime \prime}$ state. We thus expect that bands originating from the two states should be separated by only $350 \mathrm{~cm}^{-1}$, and the excited-state dynamics will be the same.

There are two additional points of interest concerning the ethoxy PFY spectrum. First, the band in Figure 1 is remarkably similar, although not identical, to the electronic absorption band assigned by Anastasi et al. ${ }^{32}$ to the 2-hydroxyethyl $\left(\mathrm{CH}_{2} \mathrm{CH}_{2}-\right.$ $\mathrm{OH})$ radical. In their experiment, a transient absorption feature resulting from the reaction of $\mathrm{OH}$ with $\mathrm{C}_{2} \mathrm{H}_{4}$ was assigned to collisionally stabilized $\mathrm{CH}_{2} \mathrm{CH}_{2} \mathrm{OH}$ adduct. However, the calculations by Schlegel et al. ${ }^{34}$ show that the isomerization barrier for $\mathrm{CH}_{2} \mathrm{CH}_{2} \mathrm{OH} \rightarrow \mathrm{CH}_{3} \mathrm{CH}_{2} \mathrm{O}$ is comparable to the entrance channel barrier for addition of $\mathrm{OH}$ to $\mathrm{C}_{2} \mathrm{H}_{4}$. This calculation suggests that some isomerization to ethoxy could occur in the experiment by Anastasi et al. Such a process would explain the similarity between our PFY spectrum, which originates solely from ethoxy radical, and their transient absorption spectrum. Our observation of the ethoxy band in Figure 1 also resolves a discrepancy in the product branching ratio of the $\mathrm{F}+\mathrm{C}_{2} \mathrm{H}_{5} \mathrm{OH}$ reaction, for which Anastasi et al. find a lower value for $\mathrm{CH}_{3}$ $\mathrm{CH}_{2} \mathrm{O}$ production relative to $\mathrm{CH}_{2} \mathrm{CH}_{2} \mathrm{OH}$ and $\mathrm{CH}_{3} \mathrm{CHOH}$ than in previous work that used isotopic labeling to distinguish among product isomers; ${ }^{48}$ Anastasi et al. obtained their branching ratios by analyzing the transient absorption from 300 to $225 \mathrm{~nm}$ and assuming the ethoxy absorption in this region was negligible.

Finally, we consider the absence of dissociation from the $\tilde{B}$ ${ }^{2} \mathrm{~A}^{\prime}$ state of ethoxy. As mentioned above, this state is similar to the $\tilde{\mathrm{A}}{ }^{2} \mathrm{~A}_{1}$ excited state of $\mathrm{CH}_{3} \mathrm{O}$, which is known to undergo predissociation to $\mathrm{CH}_{3}+\mathrm{O}$ when six or more quanta are excited in the $\mathrm{C}-\mathrm{O}$ stretch; ${ }^{47}$ this corresponds to $3791 \mathrm{~cm}^{-1}$ of vibrational excitation in the upper state. ${ }^{49}$ The $3_{0}^{6}$ transition in $\mathrm{CH}_{3} \mathrm{O}$ exhibits a shorter fluorescence lifetime than lower-energy $3_{0}^{n}$ transitions ${ }^{50}$ consistent with the onset of predissociation for the $v_{3}=6$ upper level. The predissociation results from a crossing between the bound $\tilde{\mathrm{A}}{ }^{2} \mathrm{~A}_{1}$ state and several repulsive states leading to $\mathrm{CH}_{3}+\mathrm{O} .{ }^{51}$

Because of the similarity between the $\tilde{\mathrm{A}}{ }^{2} \mathrm{~A}_{1}$ state of $\mathrm{CH}_{3} \mathrm{O}$ and the $\tilde{\mathrm{B}}{ }^{2} \mathrm{~A}^{\prime}$ state of $\mathrm{C}_{2} \mathrm{H}_{5} \mathrm{O}$, the possibility of predissociation on the $\tilde{\mathrm{B}}{ }^{2} \mathrm{~A}^{\prime}$ state of the ethoxy radical was pointed out by Inoue et al. ${ }^{22}$ In the ethoxy radical, the origin of the $\tilde{\mathrm{B}}^{2} \mathrm{~A}^{\prime} \leftarrow$ $\tilde{\mathrm{X}}^{2} \mathrm{~A}^{\prime \prime}$ transition at $29204 \mathrm{~cm}^{-1}$ is $2446 \mathrm{~cm}^{-1}$ lower in energy 
than the $\tilde{\mathrm{A}}{ }^{2} \mathrm{~A}_{1} \leftarrow \tilde{\mathrm{X}}{ }^{2} \mathrm{E}$ transition in methoxy $\left(T_{0}=31650\right.$ $\left.\mathrm{cm}^{-1}\right),{ }^{49}$ and the dissociation threshold for $\mathrm{C}-\mathrm{O}$ bond fission is about $900 \mathrm{~cm}^{-1}$ higher in ethoxy $\left(31620 \mathrm{~cm}^{-1}\right)$. As a consequence, the highest-energy ethoxy transition seen by laserinduced fluorescence $\mathrm{e}^{26}$ at $32139 \mathrm{~cm}^{-1}$ results in an excited state with five quanta in the $\mathrm{C}-\mathrm{O}$ bond that lies only $520 \mathrm{~cm}^{-1}$ above the $\mathrm{C}_{2} \mathrm{H}_{5}+\mathrm{O}$ asymptote, whereas the $v_{3}=6$ level of the $\tilde{\mathrm{A}}$ ${ }^{2} \mathrm{~A}_{1}$ in methoxy lies $4738 \mathrm{~cm}^{-1}$ above the threshold for dissociation to $\mathrm{CH}_{3}+\mathrm{O} .{ }^{47}$ Thus, if the repulsive states correlating to this asymptote are similar to those in methoxy, considerably more excitation in the $\mathrm{C}-\mathrm{O}$ stretch is needed in ethoxy for predissociation to occur, and the Franck-Condon factors for these transitions may simply be too small to be observable in our PFY spectrum.

B. Dissociation Mechanism. In our experiment, channel (4) $\left(\mathrm{C}_{2} \mathrm{H}_{5} \mathrm{O} \rightarrow \mathrm{C}_{2} \mathrm{H}_{3}+\mathrm{H}_{2} \mathrm{O}\right)$ is observed as a major dissociation channel resulting from excitation of the band in Figure 1. This result is somewhat surprising, given that several channels (2, 3 , and 6) involving simple bond fission are accessible in this energy range. Although we cannot easily detect $\mathrm{H}$ atom $\left(\right.$ or $\left.\mathrm{H}_{2}\right)$ loss with our coincidence scheme, the mass spectra with isotopic substitution in Figure 2 indicate that channel 4 dominates over channels 2, 5, and 6 .

For the ethoxy radical to dissociate into $\mathrm{C}_{2} \mathrm{H}_{3}+\mathrm{H}_{2} \mathrm{O}$, two hydrogen atoms must migrate from the carbon atom to the oxygen atom of the ethoxy radical before the dissociation. If we exclude the possibility of migration of two hydrogen atoms at the same time, the reaction path must pass through either the 1- or 2-hydroxyethyl structures en route to the possible transition states (TS) such as a four-centered (I) or three-centered (II)

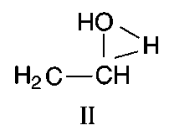

transition state. We consider possible dissociation mechanisms under this assumption.

First, we consider whether the first step in the dissociation mechanism is internal conversion of the electronically excited ethoxy radical to its ground state, followed by isomerization through either the 1- or 2-hydroxyethyl radical, passage through one of the above TS structures, and dissociation:

$$
\begin{aligned}
& \mathrm{CH}_{3} \mathrm{CH}_{2} \mathrm{O} \stackrel{\mathrm{IC}}{\longrightarrow} \mathrm{CH}_{3} \mathrm{CH}_{2} \mathrm{O} \rightarrow \mathrm{CH}_{3} \mathrm{CHOH} \rightarrow \\
& \rightarrow \mathrm{TS} \rightarrow \\
& \mathrm{C}_{2} \mathrm{H}_{3}+\mathrm{H}_{2} \mathrm{O} \\
& \stackrel{\mathrm{IC}}{\longrightarrow} \mathrm{CH}_{3} \mathrm{CH}_{2} \mathrm{O} \rightarrow \mathrm{CH}_{2} \mathrm{CH}_{2} \mathrm{OH} \rightarrow \mathrm{TS} \rightarrow \rightarrow \\
& \mathrm{C}_{2} \mathrm{H}_{3}+\mathrm{H}_{2} \mathrm{O}
\end{aligned}
$$

Figure 6 shows the relative energies of ethoxy, 1-hydroxyethyl, and 2-hydroxyethyl radicals and the isomerization barrier heights. The barriers to isomerization to either hydroxyethyl radical $(1.1-1.3 \mathrm{eV})$ are higher than those for dissociation of ethoxy to $\mathrm{CH}_{3}+\mathrm{CH}_{2} \mathrm{O}$ and $\mathrm{H}+\mathrm{CH}_{3} \mathrm{CHO}(0.8$ and $1.0 \mathrm{eV}$, respectively). Hence, dissociation to these two channels rather than isomerization is expected, and this prediction is consistent with experiments in which chemically activated ethoxy formed by the $\mathrm{O}+\mathrm{C}_{2} \mathrm{H}_{5}$ reaction dissociates exclusively to $\mathrm{CH}_{3}+$ $\mathrm{CH}_{2} \mathrm{O}$ and $\mathrm{H}+\mathrm{CH}_{3} \mathrm{CHO}$ rather than to channels such as $\mathrm{OH}$ $+\mathrm{C}_{2} \mathrm{H}_{4}$, which might be expected after isomerization to $\mathrm{CH}_{2}-$ $\mathrm{CH}_{2} \mathrm{OH}$. Overall, it appears unlikely that the products we observe result from internal conversion to ground-state ethoxy.

It is also possible that the excited ethoxy state isomerizes to a ground-state hydroxyethyl radical, creating highly vibrationally excited species that could then dissociate to $\mathrm{C}_{2} \mathrm{H}_{3}+\mathrm{H}_{2} \mathrm{O}$ via a three- or four-center transition state. However, $\mathrm{C}_{2} \mathrm{H}_{3}+\mathrm{H}_{2} \mathrm{O}$ has never been reported as a product from the $\mathrm{OH}+\mathrm{C}_{2} \mathrm{H}_{4}$ reaction, in which 2-hydroxyethyl is formed as a reactive intermediate; only channels 2 and 3 are seen. It therefore appears that isomerization to ethoxy occurs followed by dissociation to these channels. This result implies that the three-center TS needed to form $\mathrm{C}_{2} \mathrm{H}_{3}+\mathrm{H}_{2} \mathrm{O}$ from 2-hydroxyethyl is considerably higher than the barrier for isomerization to ethoxy.

Less is known experimentally about the ground-state isomerization and dissociation dynamics of $\mathrm{CH}_{3} \mathrm{CHOH}$. However, the isomerization barrier to go from 1-hydroxyethyl to ethoxy is calculated to be $1.6 \mathrm{eV},{ }^{34}$ so the four-center TS by which $\mathrm{C}_{2} \mathrm{H}_{3}$ $+\mathrm{H}_{2} \mathrm{O}$ could be produced from $\mathrm{CH}_{3} \mathrm{CHOH}$ would have to be substantially lower for this channel to dominate. Since the fourcentered TS identified in our ab initio calculation lies $3.65 \mathrm{eV}$ above $\mathrm{CH}_{3} \mathrm{CHOH}$, this mechanism can be ruled out.

These considerations lead us to propose that both isomerization and dissociation involve electronically excited potential energy surfaces, that is,

$$
\begin{aligned}
\mathrm{CH}_{3} \mathrm{CH}_{2} \mathrm{O}^{*} & \rightarrow \mathrm{CH}_{3} \mathrm{CHOH}^{*} \rightarrow \mathrm{TS} \rightarrow \mathrm{C}_{2} \mathrm{H}_{3}+\mathrm{H}_{2} \mathrm{O} \\
& \rightarrow \mathrm{CH}_{2} \mathrm{CH}_{2} \mathrm{OH}^{*} \rightarrow \mathrm{TS} \rightarrow \mathrm{C}_{2} \mathrm{H}_{3}+\mathrm{H}_{2} \mathrm{O}
\end{aligned}
$$

For either $\mathrm{A}^{\prime}$ or $\mathrm{B}^{\prime}$ to occur, isomerization and passage through the TS must be faster than either dissociation or internal conversion in the electronically excited ethoxy and hydroxyethyl radicals. These conditions imply that the excited states are bound with respect to dissociation and that the isomerization barriers and TS energies are relatively low.

Little is known about the hydroxyethyl excited states other than the absorption spectra measured by Anastasi et al. ${ }^{31,32}$ Figure 6 shows the range over which electronic excitation of ethoxy and the two hydroxyethyl radicals occurs based on the spectra of Anastasi et al. and the ethoxy PFY spectrum measured here. From this figure, it certainly appears that isomerization to electronically excited $\mathrm{CH}_{3} \mathrm{CHOH}$ is energetically favorable, whereas the excited states of $\mathrm{CH}_{2} \mathrm{CH}_{2} \mathrm{OH}$ and ethoxy are much closer in energy. The key issue here, and the one about which the least is known, is the set of barrier heights for isomerization and for the TS for dissociation to $\mathrm{C}_{2} \mathrm{H}_{3}+\mathrm{H}_{2} \mathrm{O}$. Given that isomerization to excited $\mathrm{CH}_{3} \mathrm{CHOH}$ is more downhill energetically than for ground-state ethoxy to ground-state $\mathrm{CH}_{3} \mathrm{CHOH}$, one certainly might expect a lower barrier for the excited-state process. Once in this excited state, there is certainly enough energy for dissociation to $\mathrm{C}_{2} \mathrm{H}_{3}+\mathrm{H}_{2} \mathrm{O}$, but the TS along this reaction pathway must be low enough in energy for this channel to dominate over other energetically allowed channels. We again point out that we cannot observe $\mathrm{H}$ or $\mathrm{H}_{2}$ loss with our detection scheme, so these could be major channels as well. In any case, it is clear that detailed ab initio calculations on the excited states of ethoxy and its isomers are needed to verify the proposed excited-state dissociation mechanism.

Finally, we consider the possible role of electronically excited products in the photodissociation of ethoxy. The vinyl radical has three low-lying excited electronic states. Two such states, the $\tilde{\mathrm{A}}^{2} \mathrm{~A}^{\prime \prime}$ and $\tilde{\mathrm{C}}{ }^{2} \mathrm{~A}^{\prime}$ states, have been observed in absorption spectra, ${ }^{52,53}$ and the $\tilde{\mathrm{B}}{ }^{2} \mathrm{~A}^{\prime \prime}$ state was theoretically identified. ${ }^{54}$ In our experiment, the production of these three excited states 
is energetically possible as follows:

$$
\begin{aligned}
\mathrm{C}_{2} \mathrm{H}_{5} \mathrm{O}\left(\tilde{\mathrm{X}}^{2} \mathrm{~A}^{\prime \prime}\right)+h v \rightarrow \mathrm{C}_{2} \mathrm{H}_{3}\left(\tilde{\mathrm{X}}^{2} \mathrm{~A}^{\prime}\right)+ & \mathrm{H}_{2} \mathrm{O}\left(\tilde{\mathrm{X}}^{1} \mathrm{~A}_{1}\right) \\
\Delta_{\mathrm{r}} H_{0} & =0.69 \mathrm{eV} \\
\mathrm{C}_{2} \mathrm{H}_{3}\left(\tilde{\mathrm{A}}^{2} \mathrm{~A}^{\prime \prime}\right)+ & \mathrm{H}_{2} \mathrm{O}\left(\tilde{\mathrm{X}}^{1} \mathrm{~A}_{1}\right) \\
& =3.17 \mathrm{eV} \\
\mathrm{C}_{2} \mathrm{H}_{3}\left(\tilde{\mathrm{B}}^{2} \mathrm{~A}^{\prime \prime}\right)+ & \mathrm{H}_{2} \mathrm{O}\left(\tilde{\mathrm{X}}^{1} \mathrm{~A}_{1}\right) \\
& =4.85 \mathrm{eV}(\mathrm{III}) \\
\mathrm{C}_{2} \mathrm{H}_{3}\left(\tilde{\mathrm{C}}^{2} \mathrm{~A}^{\prime}\right)+ & \mathrm{H}_{2} \mathrm{O}\left(\tilde{\mathrm{X}}^{1} \mathrm{~A}_{1}\right) \\
& \leq 5.9 \mathrm{eV}
\end{aligned}
$$

The arrows in Figure $4(h v=5.96 \mathrm{eV})$ indicate the maximum kinetic energy for each of these channels. The signal at $E_{\mathrm{T}} \geq$ $2.8 \mathrm{eV}$ must be from ground-state products. The remainder of the signal down to $E_{\mathrm{T}}=0.3 \mathrm{eV}$ cannot be assigned to a particular channel with any certainty. However, the low-energy feature at $E_{\mathrm{T}} \leq 0.3 \mathrm{eV}$ evident in Figure 4 as well as the $\mathrm{P}\left(E_{\mathrm{T}}\right)$ distributions shown in Figures 3 at photon energies $\geq 5.51 \mathrm{eV}$ most likely do correspond to electronically excited $\mathrm{C}_{2} \mathrm{H}_{3}$. Based on the above energetics, channel III is the closest lying channel that is open at all photon energies where this feature is observed. However, the dissociation energy given for channel IV is based on the red edge of the broad absorption spectrum observed for the $\tilde{\mathrm{X}}{ }^{2} \mathrm{~A}^{\prime} \leftarrow \tilde{\mathrm{X}}{ }^{2} \mathrm{~A}^{\prime}$ transition of $\mathrm{C}_{2} \mathrm{H}_{3}$ radical and is only an upper bound. Therefore, channel IV cannot be excluded as the origin of the low-energy feature. In any case, the appearance of the low-energy feature in the $\mathrm{P}\left(E_{\mathrm{T}}\right)$ distributions coincides with the abrupt increase in the PFY yield at $225 \mathrm{~nm}$, indicating that the excited state of ethoxy radical accessed at that wavelength preferentially dissociates to either III or IV.

\section{Conclusions}

The photodissociation spectroscopy and dynamics of ethoxy radicals were studied using fast radical beam photofragment translational spectroscopy. The photofragment yield (PFY) spectrum in the range of $270-220 \mathrm{~nm}$ is structureless but clearly exhibits abrupt increases in intensity at 260 and $225 \mathrm{~nm}$. These are tentatively assigned as two different electronic transitions. No significant dissociation signal was observed in the region where the fluorescence from the $\tilde{\mathrm{X}}^{2} \mathrm{~A}^{\prime} \rightarrow \tilde{\mathrm{X}}^{2} \mathrm{~A}^{\prime \prime}$ transition of $\mathrm{C}_{2} \mathrm{H}_{5} \mathrm{O}$ radicals was observed, indicating that the $\tilde{\mathrm{X}}^{2} \mathrm{~A}^{\prime}$ state of $\mathrm{C}_{2} \mathrm{H}_{5} \mathrm{O}$ is not dissociative.

The photofragment mass distribution shows that the major dissociation channel is $\mathrm{C}_{2} \mathrm{H}_{3}+\mathrm{H}_{2} \mathrm{O}$. Most of the $\mathrm{P}\left(E_{\mathrm{T}}\right)$ distributions for $\mathrm{C}_{2} \mathrm{H}_{3}+\mathrm{H}_{2} \mathrm{O}$ from $\mathrm{C}_{2} \mathrm{H}_{5} \mathrm{O}$ dissociation show a single feature, peaking around $0.7 \mathrm{eV}$ and extending up to 4 $\mathrm{eV}$. However, at photon energies beyond the onset of the second electronic band ( $225 \mathrm{~nm}$ or $5.51 \mathrm{eV})$, a new feature appears at $E_{\mathrm{T}} \leq 0.3 \mathrm{eV}$ that is attributed to production to an excited state of $\mathrm{C}_{2} \mathrm{H}_{3}$.

The observation of $\mathrm{C}_{2} \mathrm{H}_{3}+\mathrm{H}_{2} \mathrm{O}$ products is surprising, because two hydrogen atoms must move before the dissociation. We propose a dissociation mechanism in which the excited ethoxy radicals isomerize through excited states of either the 1- or 2- hydroxyethyl radicals and then undergo dissociation to $\mathrm{C}_{2} \mathrm{H}_{3}+\mathrm{H}_{2} \mathrm{O}$. Confirmation of this mechanism would be greatly aided by further ab initio work on the excited states of ethoxy and its isomers.
Acknowledgment. This research is supported by the Director, Office of Energy Research, Office of Basic Energy Sciences, Chemical Sciences Division, of the U.S. Department of Energy under Contract No. DE-AC03-76SF00098.

\section{References and Notes}

(1) Morris, E. D., Jr.; Stedman, D. H.; Niki, H. J. Am. Chem. Soc. 1971, 93, 3570 .

(2) Smith, I. W.; Zellner, R. J. J. Chem. Soc., Faraday Trans. 2 1973, 69, 1617

(3) Pastrana, A. V.; Carr, R. W., Jr. J. Phys. Chem. 1975, 79, 765.

(4) Overend, R.; Paraskevpoulos, G. J. Chem. Phys. 1977, 67, 674.

(5) Howard, C. J. J. Chem. Phys. 1976, 65, 4771.

(6) Lloyd, A. C.; Darnall, K. R.; Winer, A. M.; Pitts, J. N., Jr. J. Phys. Chem. 1976, 80, 789.

(7) Greiner, N. R. J. Chem. Phys. 1970, 53, 1284.

(8) Gordon, S.; Mulac, N. A. Int. J. Chem. Kinet. Symp. 1975, 1, 289.

(9) Davis, D. D.; Fischer, S.; Schiff, R.; Watson, R. T.; Bolliner, W. J. J. Chem. Phys. 1975, 65, 1707.

(10) Cox, R. A. Int. J. Chem. Kinet. Symp. 1975, 1, 379.

(11) Atkinson, R.; Perry, R. A.; Pitts, J. N., Jr. J. Chem. Phys 1977, 66, 1197.

(12) Zellner, R.; Lorenz, K. J. Phys. Chem. 1984, 88, 984.

(13) Tully, F. P. Chem. Phys. Lett. 1983, 96, 148.

(14) Klein, T.; Barnes, I.; Becker, K. H.; Fink, E. H.; Zabel, F. J. Phys. Chem. 1984, 88, 5020.

(15) Bradley, J. N.; Capey, W. D.; Fair, R. W.; Pritchard, D. K. Int. J. Chem. Kinet. 1976, 8, 549 .

(16) Batt, L.; Milne, R. T. Int. J. Chem. Kinet. 1977, 9, 549.

(17) Slagle, I. R.; Sarzynski, D.; Gutman, D.; Miller, J. A.; Melius, C. F. J. Chem. Soc., Faraday Trans. 2 1988, 84, 491.

(18) Hoyermann, K.; Olzmann, M.; Seeba, J.; Viskolcz, B. J. Phys. Chem. A 1999, 103, 5692.

(19) Caralp, F.; Devolder, P.; Fittschen, C.; Gomez, N.; Hippler, H.; Mereau, R.; Rayez, M. T.; Striebel, F.; Viskolcz, B. Phys. Chem. Chem. Phys. 1999, 1, 2935.

(20) Osborn, D. L.; Leahy, D. J.; Ross, E. M.; Neumark, D. M. Chem. Phys. Lett. 1995, 235, 484.

(21) Ohbayashi, K.; Akimoto, H.; Tanaka, I. J. Phys. Chem. 1977, 81, 798.

(22) Inoue, G.; Okuda, M.; Akimoto, H. J. Chem. Phys. 1981, 75, 2060.

(23) Ebata, T.; Yanagishita, H.; Obi, K.; Tanaka, I. Chem. Phys. 1982, $69,27$.

(24) Foster, S. C.; Hsu, Y.; Damo, C. P.; Liu, X.; Kung, C.; Miller, T. A. J. Phys. Chem. 1986, 90, 6766 .

(25) Tan, X. Q.; Williamson, J. M.; Foster, S. C.; Miller, T. A. J. Phys. Chem. 1993, 97, 9311.

(26) Zhu, X.; Kamal, M. M.; Misra, P. Pure Appl. Opt. 1996, 5, 1021.

(27) Ruscic, B.; Berkowitz, J. J. Chem. Phys. 1994, 101, 10936-19846.

(28) Ellison, G. B.; Engelking, P. C.; Lineberger, W. C. J. Chem. Phys. 1982, 86, 4873

(29) Ramond, T. M.; Davico, G. E.; Schwartz, R. L.; Lineberger, W. C. J. Chem. Phys. 2000, 112, 1158.

(30) Dang, T. T.; Motell, E. L.; Travers, M. J.; Clifford, E. P.; Ellison, G. B.; Depuy, C. H.; Bierbaum, V. M. Int. J. Mass Spectrom. Ion Processes 1993, 123, 171.

(31) Anastasi, C.; Simpson, V.; Munk, J.; Pagsberg, P. Chem. Phys. Lett. 1989, 164, 18

(32) Anastasi, C.; Simpson, V.; Munk, J.; Pagsberg, P. J. Phys. Chem. 1990, 94, 6327.

(33) Dyke, J. M.; Grooves, A. P.; Lee, E. P. F.; Zamanpour Niavaran, M. H. J. Phys. Chem. A 1997, 101, 373.

(34) Sosa, C.; Schlegel, H. B. J. Am. Chem. Soc. 1987, 109, 7007.

(35) Gonzalez, C.; Sosa, C.; Schlegel, H. B. J. Phys. Chem. 1989, 93, 2435.

(36) Curtiss, L. A.; Lucas, D. J.; Pople, J. A. J. Chem. Phys. 1995, 102, 3292.

(37) Chiu, S.-W.; Lau, K.; Li, W. J. Phys. Chem. A 1999, 103, 6003.

(38) Continetti, R. E.; Cyr, D. R.; Metz, R. B.; Neumark, D. M. Chem. Phys. Lett. 1991, 182, 406-411.

(39) Cyr, D. R.; Continetti, R. E.; Metz, R. B.; Osborn, D. L.; Neumark, D. M. J. Chem. Phys. 1992, 97, 4937-4947.

(40) Osborn, D. L.; Leahy, D. J.; Cyr, D. R.; Neumark, D. M. J. Chem. Phys. 1996, 104, 5026.

(41) Osborn, D. L.; Mordaunt, D. H.; Choi, H.; Bise, R. T.; Neumark, D. M. J. Chem. Phys. 1997, 106, 10087.

(42) Continetti, R. E.; Cyr, D. R.; Osborn, D. L.; Leahy, D. J.; Neumark, D. M. J. Chem. Phys. 1993, 99, 2616. 
(43) Ervin, K. M.; Gronert, S.; Barlow, S. E.; Giles, M. K.; Harrison, A. G.; Bierbaum, V. M.; DePuy, C. H.; Lineberger, W. C.; Ellison, G. B. J. Am. Chem. Soc. 1990, 112, 5750.

(44) Lias, S. G.; Bartmess, J. E.; Liebman, J. F.; Holmes, J. L.; Levin, R. D.; Mallard, W. G. Gas-Phase Ion and Neutral Thermochemistry. $J$. Chem. Phys. Ref. Data 1985, 17, Suppl. No. 1.

(45) Chase, Jr., M. W.; Davies, C. A.; Downey, Jr., J. R.; Fruip, D. J.; McDonald, R. A.; Syverud, A. N. JANAF Thermochemical Tables, 3rd ed. J. Chem. Phys. Ref. Data 1985, 14, Suppl. No. 1.

(46) Frisch, M. J.; Trucks, G. W.; Head-Gordon, M.; Gill, P. M. W.; Wong, M. W.; Foresman, J. B.; Johnson, B. G.; Schlegel, H. B.; Robb, M. A.; Replogel, E. S.; Gomperts, R.; Andres, J. L.; Raghavachari, K.; Binkley, J. S.; Gonzalez, C.; Martin, R. L.; Fox, D. J.; Defrees, D. J.; Baker, J.; Stewart, J. J. P.; Pople, J. A. GAUSSIAN 92, Revision C; Gaussian Inc.: Pittsburgh, PA, 1992.
(47) Osborn, D. L.; Leahy, D. J.; Neumark, D. M. J. Phys. Chem. A 1997, 101, 6583 .

(48) Meier, U.; Grotheer, H. H.; Riekert, G.; Just, T. Chem. Phys. Lett. 1985, 115, 221

(49) Foster, S. C.; Misra, P.; Lin, T.-Y. D.; Damo, C.; Carter, C. C.; Miller, T. A. J. Phys. Chem. 1988, 92, 5914.

(50) Powers, D. E.; Pushkarsky, M. B.; Miller, T. A. J. Chem. Phys. 1997, 106, 6878 .

(51) Cui, Q.; Morokuma, K. Chem. Phys. Lett. 1996, 263, 54

(52) Hunziker, H. E.; Kneppe, H.; McLean, A. D.; Siegbahn, P.; Wendt, H. R. Can. J. Chem. 1983, 61, 993.

(53) Fahr, A.; Hassanzadeh, P.; Atkinson, D. B. Chem. Phys. 1998, 236, 43.

(54) Mebel, A. M.; Chen, Y.; Lin, S. Chem. Phys. Lett. 1997, 275, 19 